\title{
Damage severity for cracked simply supported beams
}

\author{
Ehab Samir Mohamed Mohamed Soliman \\ Mechatronics and Robotics Department, Faculty of Engineering, Egyptian Russian University, Badr City, Cairo, 11829, Egypt. \\ swgezumo@yahoo.com, bttp:/ / orcid.org/0000-0001-6427-3022
}

\begin{abstract}
This paper investigated the static and dynamic behaviors of isotropic cracked simply supported beam using finite element analysis (FEA), ANSYS software. Modal and harmonic vibration analysis of intact and damaged beam were performed in order to extract mode shapes of bending vibration, natural frequencies and obtain frequency response diagram. Static finite element analysis of undamaged and damaged simply supported beam was carried out to determine static deflection, then stiffness of intact and cracked beam was computed using conventional formula. Crack damage severity of damaged beam was calculated and it is noticed that as crack position is increased from left hand support of beam up to central point and crack depth is increased, then crack damage severity increases. The effect of mode shape pattern is investigated and it is found that the amount of decreasing of natural frequency is proportional to the normalized mode shape at position of crack. The exhibited correlation between results for damaged beam revealed that crack damage severity is proportional to static deflection and inversely proportional to first mode frequency.
\end{abstract}

KEYWORDS. Isotropic; Damaged simply supported beam; Crack damage severity; Mode shape; Static deflection.

\section{${ }_{\text {open }}$ Access \\ Citation: Soliman, E.S.M.M., Damage severity for cracked simply supported beams, Frattura ed Integrità Strutturale, 58 (2021) $151-165$.}

Received: 26.07 .2021

Accepted: 21.08 .2021

Published: 01.10.2021

Copyright: (C) 2021 This is an open access article under the terms of the CC-BY 4.0, which permits unrestricted use, distribution, and reproduction in any medium, provided the original author and source are credited.

\section{INTRODUCTION}

$\mathrm{S}$ tructures must work in safety during service life but the initiation of a breakdown period on it is due to damages as cracks [1]. Crack may be caused by manufacturing and material defects and furthermore, fatigue cracks in structures are easily triggered under periodical alternating loads in operating conditions [2]. The mass and stiffness distributions of the structure are to be an effective on the dynamic behavior of the structure, i.e., dynamic response, natural frequencies and mode shapes of a structure [3]. Vibration-based inspection methodology is one of the modern approaches to non-destructive testing and evaluation (NDE) [4]. A noticeable shift in the natural frequencies is revealed by plotting the deformation responses in the Y-direction for the intact and cracked cantilever beams [5]. The effects of the developed damage in the structure are the reduction of the rigidity of the structure and altering the associated dynamic and static properties to some extent [6]. For monitoring the crack, mostly modal frequencies are used where modal frequencies are properties of the whole component [7]. A change in model parameters i.e. model frequencies, model damping values and mode shapes associated with each model frequencies characterizes the change in dynamic characteristics of damaged structures [8]. The reduction of natural frequency of the component occurs as a result of crack 
and by measuring the change in the natural frequencies of the component due to crack, many methods have been developed to identify the crack [7]. The complex structures are decomposed into simple elements such as beams, columns and plates using the structural elements during the machine design process and the functioning of the whole machine may stop due to failure of any small component [9]. Khalkar and Ramachandran [10] carried out static and modal analyses for intact and cracked cantilever beam by ANSYS software to get static deflection and natural frequency. They determined stiffness of intact and various cracked cases of a cantilever beam based on results of ANSYS static deflection. Through this research study [10], it is found that when the crack position is kept constant and crack depth is increased, then stiffness of the beam decreases and when the crack depth is kept constant and crack position is varied from the fixed end, then stiffness of the beam increases. In this work, the damaged simply supported beam with single edge crack is investigated for its natural frequencies of bending vibration modes, mode shape pattern of bending vibration, static deflection and stiffness to study crack damage severity. Also, the correlation between results of crack damage severity and results of dynamic and static parameters are investigated.

\section{METHODOLOGY}

I $\mathrm{n}$ this study, the cracked simply supported beam is considered as an Euler-Bernoulli beam. The crack is uniformly extending along the damaged beam width and the crack is considered as fully open edge. The material of damaged and undamaged beams used in the analysis is considered as isotropic and homogeneous. The governing differential equation of the free transverse vibration of an undamaged Euler-Bernoulli beam without crack which is uniform, isotropic and homogeneous can be written as [11]:

$$
\frac{\partial^{4} y(x, t)}{\partial x^{4}}+\frac{\rho A}{E I} \frac{\partial^{2} y(x, t)}{\partial t^{2}}=0
$$

where the origin of $\mathrm{x}$ and $\mathrm{y}$ is at left end of the beam, $\mathrm{y}(\mathrm{x}, \mathrm{t})$ is the function of the transverse displacements, $\mathrm{E}$ is modulus of elasticity, I is the area moment of inertia, @ is mass density, A is the cross-sectional area and $t$ is time. According to [12], for solution Eqn. (1), assume that:

$$
y(x, t)=Y(x) e^{j \omega t}
$$

where $j=\sqrt{-1}, \omega$ is natural frequency of the beam.

By substituting Eqn. (2) into Eqn. (1), then Eqn. (3) can be expressed as [12]:

$$
\begin{aligned}
& \frac{\partial^{4} Y(\zeta)}{\partial x^{4}}+\lambda^{4} Y(\zeta)=0 \\
& \lambda=\left(\frac{\omega^{2} \rho A L^{4}}{E I}\right)^{1 / 4}
\end{aligned}
$$

where $\zeta=\mathrm{x} / \mathrm{L}$ is normalized location, $\mathrm{x}$ is the coordinate and its origin at left end of beam and $\lambda$ is non-dimensional frequency parameter.

According to [12], the general solution of Eqn. (3) can be written as the following:

$$
Y(\zeta)=A \cos (\lambda \zeta)+B \sin (\lambda \zeta)+C \cosh (\lambda \zeta)+D \sinh (\lambda \zeta)
$$

The damaged beam can be simulated as two uniform beam segments, joined by a torsional spring at the position of crack [13]. The modes of harmonic vibration for these two beam segments can be written as [12]: 


$$
\begin{aligned}
& Y_{1}(\zeta)=A_{1} \cos (\lambda \zeta)+B_{1} \sin (\lambda \zeta)+C_{1} \cosh (\lambda \zeta)+D_{1} \sinh (\lambda \zeta) \\
& Y_{2}(\zeta)=A_{2} \cos (\lambda \zeta)+B_{2} \sin (\lambda \zeta)+C_{2} \cosh (\lambda \zeta)+D_{2} \sinh (\lambda \zeta)
\end{aligned}
$$

where $A_{i}$ and $B_{i}, i=1,2,3,4$, are coefficients can be obtained from the boundary conditions.

The boundary conditions for the simply supported beam at the supports are [12]

At the supports no displacement and no moments:

$$
\begin{aligned}
& \left.Y_{1}\right|_{\zeta=0}=0 \\
& \left.Y_{2}\right|_{\zeta=1}=0 \\
& \left.\frac{d^{2} Y_{1}}{d \zeta^{2}}\right|_{\zeta=0}=0 \\
& \left.\frac{d^{2} Y_{2}}{d \zeta^{2}}\right|_{\zeta=1}=0
\end{aligned}
$$

If $\zeta=\mu=\mathrm{Lc} / \mathrm{L}$ is the normalized crack position, Lc is the crack distance from left hand support, the continuity conditions at the crack position are [12]:

$$
\begin{aligned}
& \text { Displacement: }\left.\quad Y_{1}\right|_{\zeta=\mu}=\left.Y_{2}\right|_{\zeta=\mu} \\
& \text { Moment: }\left.\quad E I \frac{d^{2} Y_{1}}{d \zeta^{2}}\right|_{\zeta=\mu}=\left.E I \frac{d^{2} Y_{2}}{d \zeta^{2}}\right|_{\zeta=\mu} \\
& \text { Shear force: }\left.E I \frac{d^{3} Y_{1}}{d \zeta^{3}}\right|_{\zeta=\mu}=\left.E I \frac{d^{3} Y_{2}}{d \zeta^{3}}\right|_{\zeta=\mu}
\end{aligned}
$$

Compatibility condition i.e., jump in the slope at the crack location due to rotational flexibility can be defined as [14]:

$$
\left.\frac{d Y_{1}}{d \zeta}\right|_{\zeta=\mu}+\left.\left(E / K_{T}\right) \frac{d^{2} Y_{1}}{d \zeta^{2}}\right|_{\zeta=\mu}=\left.\frac{d Y_{2}}{d \zeta}\right|_{\zeta=\mu}
$$

$\mathrm{K}_{\mathrm{T}}$ is the bending spring constant at cracked section and it is, originally calculated by [15] and can be written as [14]:

$$
\begin{aligned}
& K_{T}=1 / c \\
& c=(5.346 h / E I) f(s / h)
\end{aligned}
$$




$$
\begin{aligned}
f(s / h)= & 1.8624(s / h)^{2}-3.95(s / h)^{3}+16.3754(s / h)^{4}-37.226(s / h)^{5} \\
& +76.81(s / h)^{6}-126.9(s / h)^{7}+172(s / h)^{8}-143.97(s / h)^{9}+66.562(s / h)^{10}
\end{aligned}
$$

where $\mathrm{c}$ is compliance, $f(s / h)$ is dimensionless local compliance function, $\mathrm{s}$, is depth of crack and $\mathrm{h}$, is height of beam. According to elementary beam theory, Sayyad and Kumar [13] are expressed the relationship between the changes in Eigen frequency and the crack location and stiffness of crack for a simply supported beam as the following:

$$
\Delta f_{n} / f_{n}=\sin ^{2}(n \pi x) E I / K_{T} L
$$

where $\Delta f_{n}$ is the difference of Eigen frequencies between un-cracked and cracked beams and $\mathrm{n}$ is number of bending mode. From Eqns. (16), (17), (18) and (19) the following equation can be extracted as [13]:

$$
\Psi^{2}=(s / h)^{2}=\frac{\Delta f_{n} / f_{n}}{9.9563 \cdot \sin ^{2}[n \cdot \pi \cdot(\mu+1) / 2] \cdot \frac{b}{L}}
$$

Single characteristic equation for simply supported beam with a single crack can be expressed as [16]:

$$
\begin{aligned}
& K_{0}=\frac{\lambda}{2}\left(\frac{\cos (\lambda-2 \lambda \beta)-\cos \lambda}{2 \sin \lambda}+\frac{\operatorname{ch}(\lambda-2 \lambda \beta)-\operatorname{ch} \lambda}{2 \operatorname{sh} \lambda}\right) \\
& K_{0}=K_{T} L /(E I)
\end{aligned}
$$

where $\mathrm{K}_{0}$ is non-dimensional stiffness of the rotational spring.

If $\mathrm{F}$ is zero frequency applied load at midpoint of beam, the deflection at the center point of simply supported beam can be written as [17]:

$$
\delta=\frac{F L^{3}}{48 E I}
$$

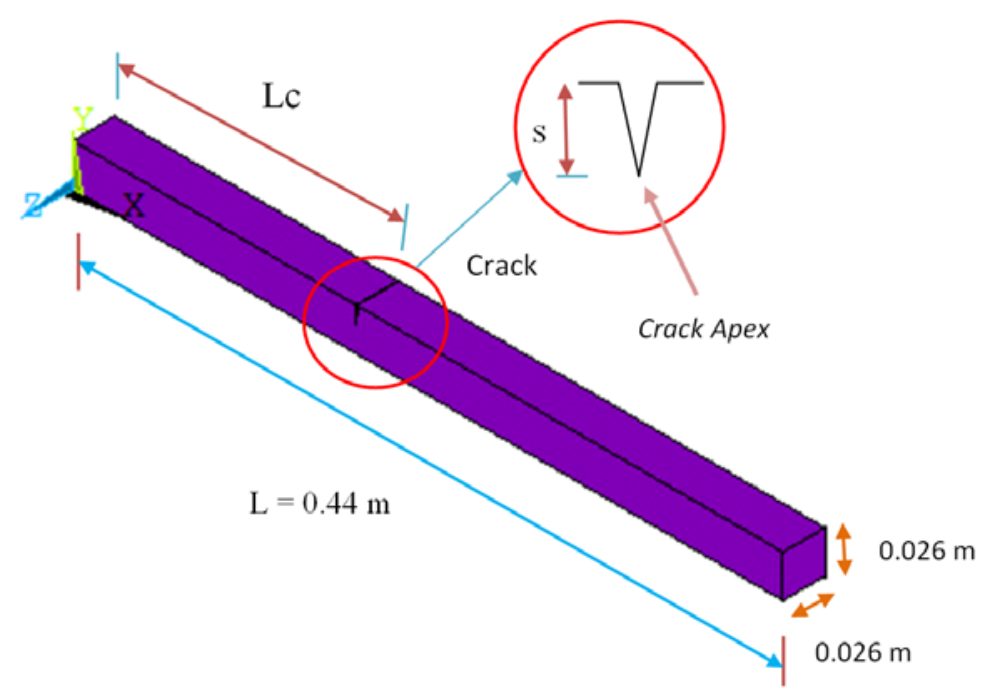

Figure 1: Model of damaged simply supported beam. 


\section{MODEL OF DAMAGED BEAM}

$\mathrm{I}$ $\mathrm{n}$ this study, an aluminum damaged simply supported beam model with single open edge crack of depth (s) at distance (Lc) from left hand support of beam as shown in Figure 1 is used to determine crack damage severity and modal parameters for cracked beam. The geometry properties of the undamaged and damaged beam are length $(\mathrm{L})=$ $0.44 \mathrm{~m}$, and cross-sectional area $(\mathrm{A})=0.026 \times 0.026 \mathrm{~m}^{2}$. The crack location ratio $\mu$ is defined as $\mu=\mathrm{Lc} / \mathrm{L}$ and crack depth ratio $\Psi$ is defined as $\Psi=\mathrm{s} / \mathrm{h}$, where $(\mathrm{h})$ is height of beam. The material properties of the undamaged and damaged beam are Young's modulus of elasticity $(E)=70 \mathrm{GPa}$, Poisson's ratio $(v)=0.346$ and density $(\varrho)=2710 \mathrm{~kg} / \mathrm{m}^{3}$. In order to consider different damage scenarios of the beam in the analysis, crack location ratio $0.1,0.3$ and 0.4 are chosen and for each crack location ratio crack depth ratio is varied as $0.2,0.3$ and 0.4 .
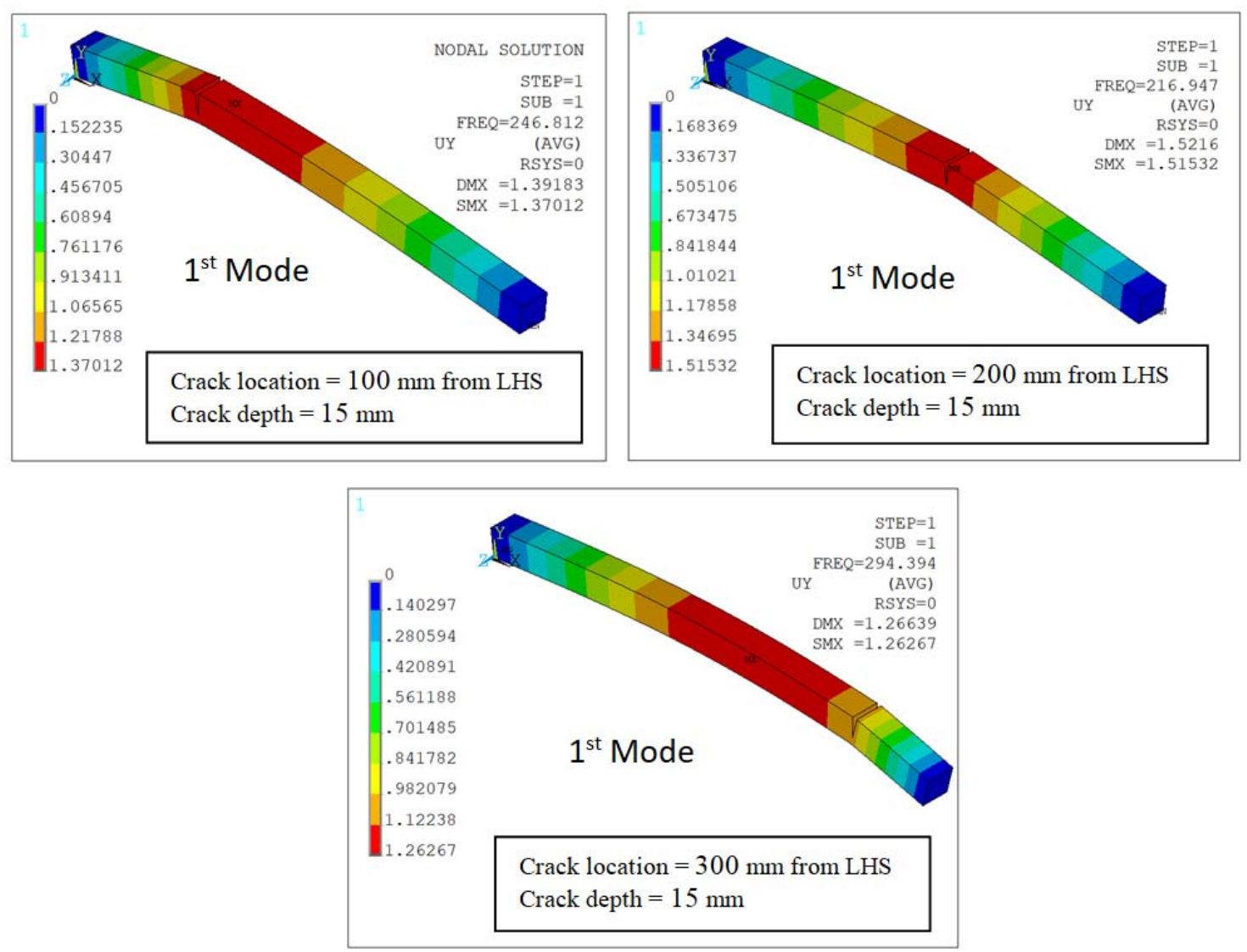

Figure 2: FEA results of frequency of first mode

\section{VALIDATION}

$\mathrm{I}$

$\mathrm{n}$ order to validate the developed model used in this study, the results of FEA frequency of the first mode of bending vibration for different three scenarios of cracked simply supported beam used by Khalkar [17] is obtained (see Figure 2), comparing it with those available in the literature as shown in Fig. 3. The following beam and crack parameters are given in Table 1 [17]. The solid 186 element is adopted for meshing the 3D model of cracked simply supported beam in the finite element analysis. In the analysis for the three scenarios of cracked beam, the location of crack is measured from left hand support of beam (LHS) as considered in [17]. From Figure 3, it is found that FEA results meet with excellent agreement with the results already published by Khalkar [17] and thus verifies the precise of results of finite element analysis (FEA) used in this study. 


\begin{tabular}{cc}
\hline Parameter & Value \\
Elastic modulus & $2.104 \times 10^{11} \mathrm{~N} / \mathrm{m}^{2}$ \\
Density & $7820 \mathrm{~kg} / \mathrm{m}^{3}$ \\
Poisson's ratio & 0.3 \\
Beam length & $0.36 \mathrm{~m}$ \\
Beam cross sectional area & $0.02 \times 0.02 \mathrm{~m}^{2}$ \\
\hline
\end{tabular}

Table 1: Beam and crack parameters [17]

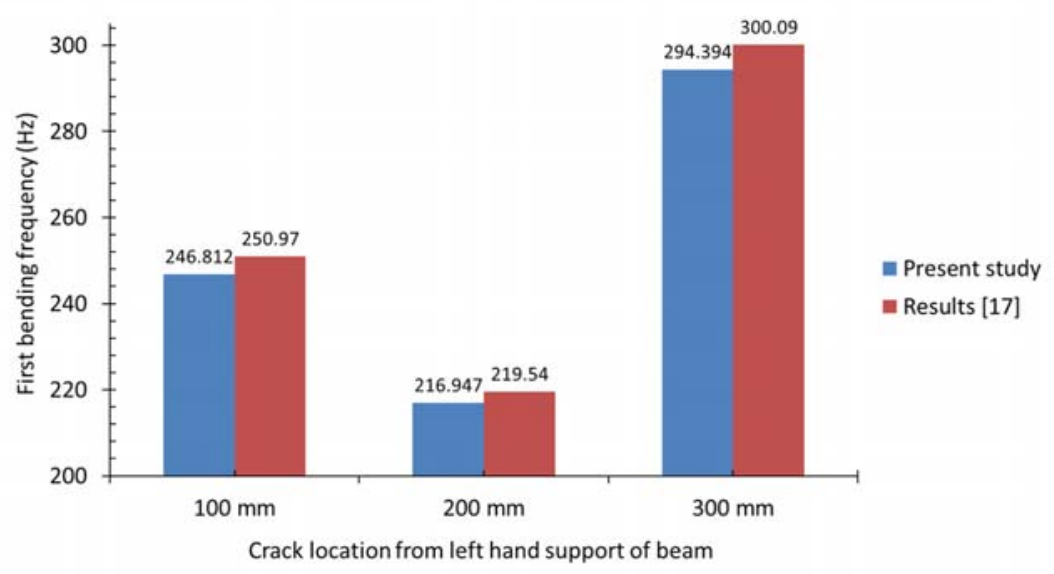

Figure 3: Comparison of the results of first mode frequency
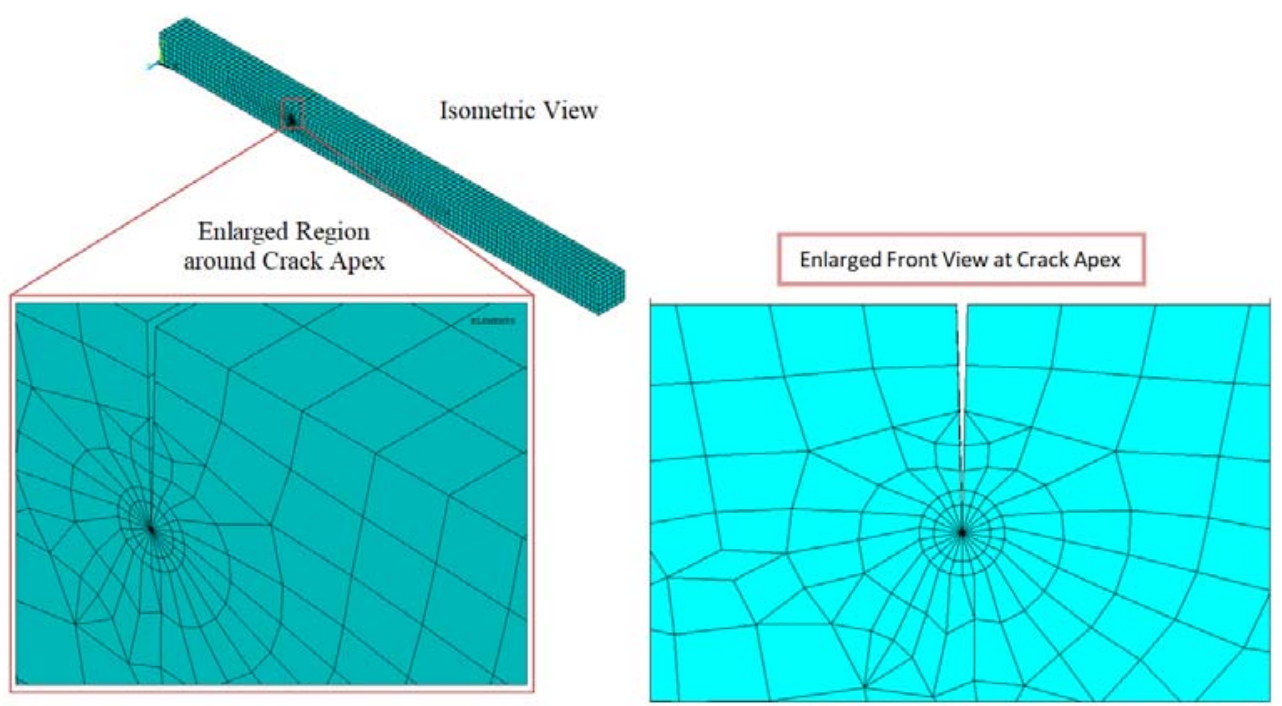

Figure 4: Finite element model of damaged simply supported beam: $\mu=0.3, \Psi=0.4$

\section{NUMERICAL ANALYSIS}

7 he numerical analysis is carried out for both undamaged and damaged beams using finite element analysis (FEA), ANSYS. In the analysis, modal and static analysis respectively are used to obtain mode shapes of bending 1 vibration and static deflection, respectively. Harmonic analysis is carried out to see difference between frequencies of undamaged and damaged beams in the frequency response diagram. In the static and harmonic analysis load of $300 \mathrm{~N}$ is applied at the central point of the simply supported beam. A 20 node structural solid element (solid 186) was adopted in the analysis to model the beam. A special mesh around the crack tip was established with singular elements surrounding the crack apex (see Figure 4). 


\section{MODE EXTRACTION AND HARMONIC FREQUENCY}

$\mathrm{I}$ $\mathrm{n}$ modal analysis, the block Lanczos method was used to estimate frequencies of first two mode shapes of bending vibration for undamaged and damaged beams. The first natural frequencies of damaged beams are calculated analytically using Eq. 20 [13] and compared with those of FEA. As depicted in Table 2, it is found that analytical results have been met with good agreement with the FEA results and thus validates the precise of developed model used in this study.

\begin{tabular}{ccccc}
\hline $\begin{array}{c}\text { Crack location } \\
\text { ratio }(\mu)\end{array}$ & $\begin{array}{c}\text { Crack depth } \\
\text { ratio }(\Psi)\end{array}$ & \multicolumn{2}{c}{ First natural frequency $(\mathrm{Hz})$} & Variation (\%) \\
\hline 0.1 & 0.2 & 302.39 & FEA & -0.4 \\
0.1 & 0.3 & 294.13 & 303.648 & -2.9 \\
0.1 & 0.4 & 283.3 & 302.708 & -6.3 \\
0.2 & 0.2 & 302.9 & 301.155 & 0.3 \\
0.2 & 0.3 & 295.2 & 302 & -1.2 \\
0.2 & 0.4 & 285.1 & 298.82 & -3 \\
0.3 & 0.2 & 303.66 & 293.71 & 1.2 \\
0.3 & 0.3 & 296.87 & 299.978 & 0.9 \\
0.3 & 0.4 & 287.8 & 294.298 & 0.8 \\
0.4 & 0.2 & 304.6 & 285.407 & 2 \\
0.4 & 0.3 & 298.97 & 298.418 & 2.7 \\
0.4 & 0.4 & 291.39 & 290.861 & 4.1 \\
0.5 & 0.2 & 305.7 & 279.35 & 2.6 \\
0.5 & 0.3 & 301.4 & 297.85 & 3.9 \\
0.5 & 0.4 & 295.4 & 289.63 & 6.2 \\
Healthy un-damaged beam & 309.34 & 277.23 & 1.6 \\
\hline
\end{tabular}

Table 2: Comparison between analytical and numerical results

Finite element analysis (FEA) results for the first two mode of bending vibration for some scenarios of damaged beam are depicted in Figures 5, 6 and 7. Figures 8 and 9 show the plotted of first two frequencies of bending mode as a function of crack location ratio for varying crack depth ratio. The influence of crack location ratio and crack depth ratio on first two frequencies of bending mode is indicated in Figures 10 and 11. From Figures 8, 9,10 and 11 it is observed the following:

1- When the crack depth ratio is kept constant and crack location ratio is increased from the left hand support of the simply supported beam, then first frequency of bending mode decreases up to central point of the beam.

2- When the crack depth ratio is kept constant and crack location ratio is increased from the beam midpoint towards the right hand support of the beam, then first frequency of bending mode increases.

3- For the second mode of bending vibration, when the crack depth ratio is kept constant the decreasing of frequency is the following ways: (a) at $\mu=0.1$, it is moderate decreasing, (b) at $\mu=0.3$, it is maximum decreasing, and (c) at $\mu=0.4$, it is minimum decreasing.

The amount of decreasing frequencies for damaged beam is showed as shift between frequencies of damaged and undamaged beams in frequency response diagram as indicated in Figures 12 and 13. The shift between frequencies of damaged and undamaged beams can be expressed as:

$$
\partial f_{n}=f_{n}-f_{c n}
$$

where $\mathrm{n}$ is number of bending mode, $f$ is un-damaged beam frequency and $f_{\mathrm{c}}$ is damaged beam frequency. 

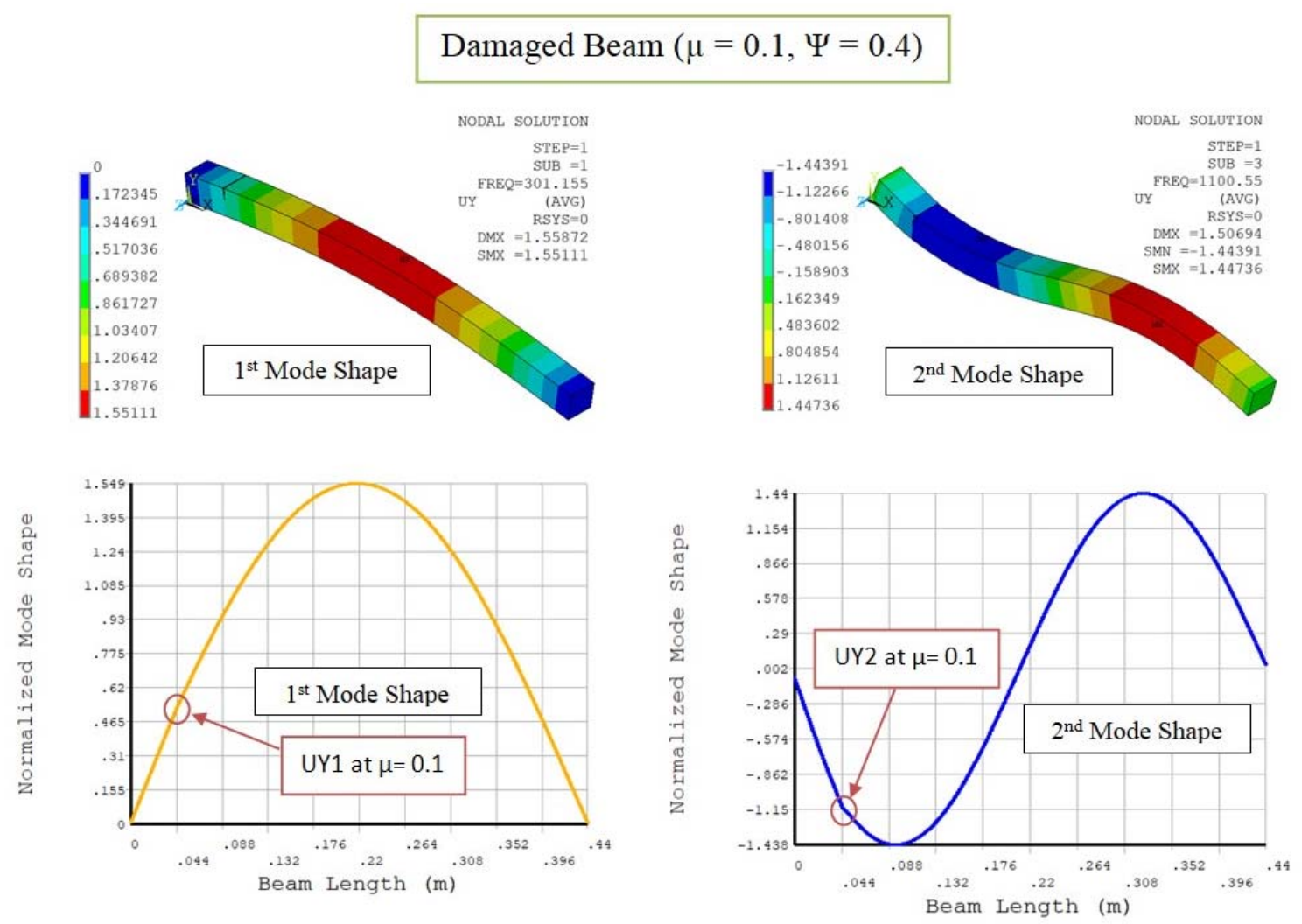

Figure 5: FEA results of first two mode shapes of bending vibration for damaged beam: $\mu=0.1, \Psi=0.4$

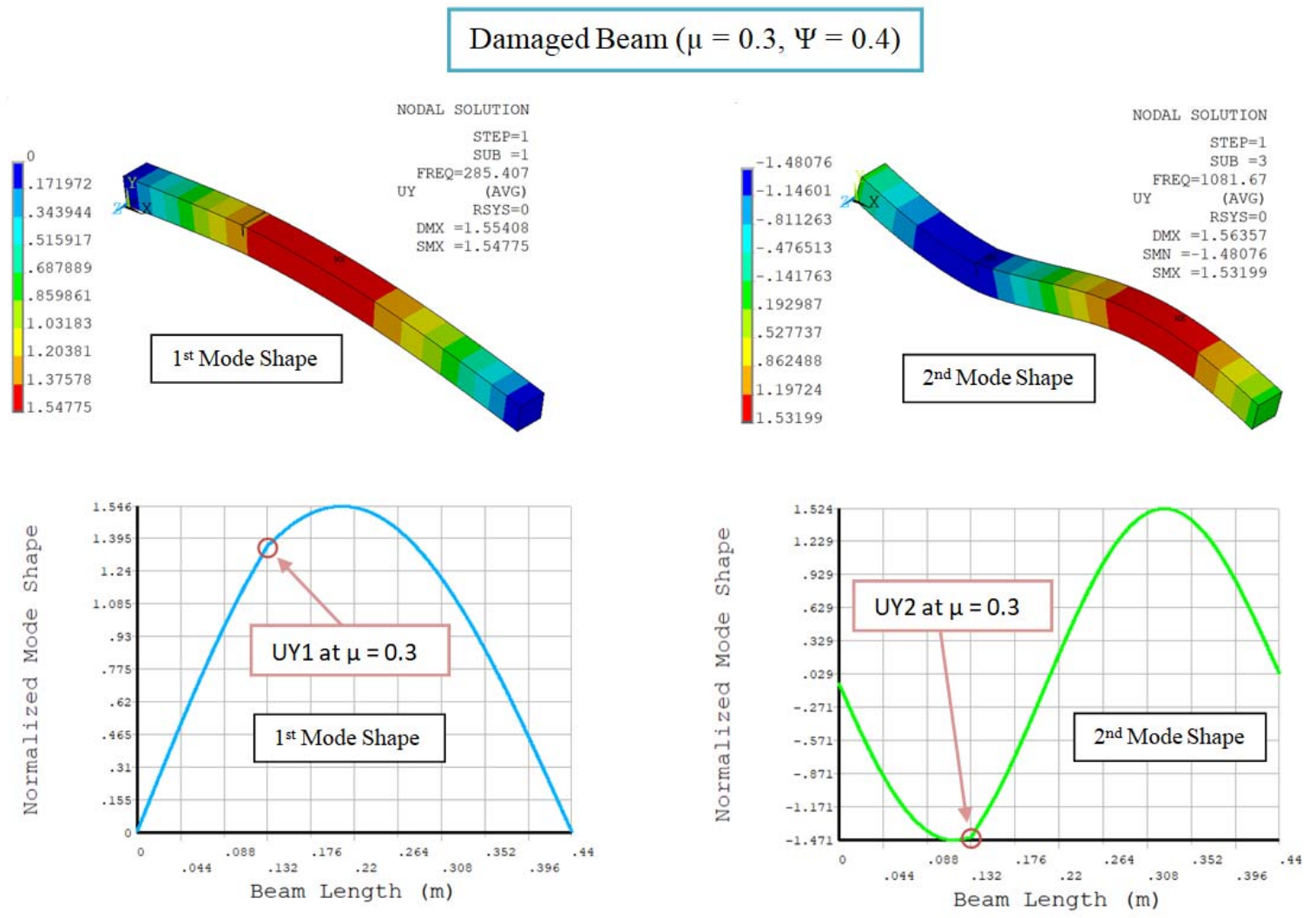

Figure 6: FEA results of first two mode shapes of bending vibration for damaged beam: $\mu=0.3, \Psi=0.4$ 


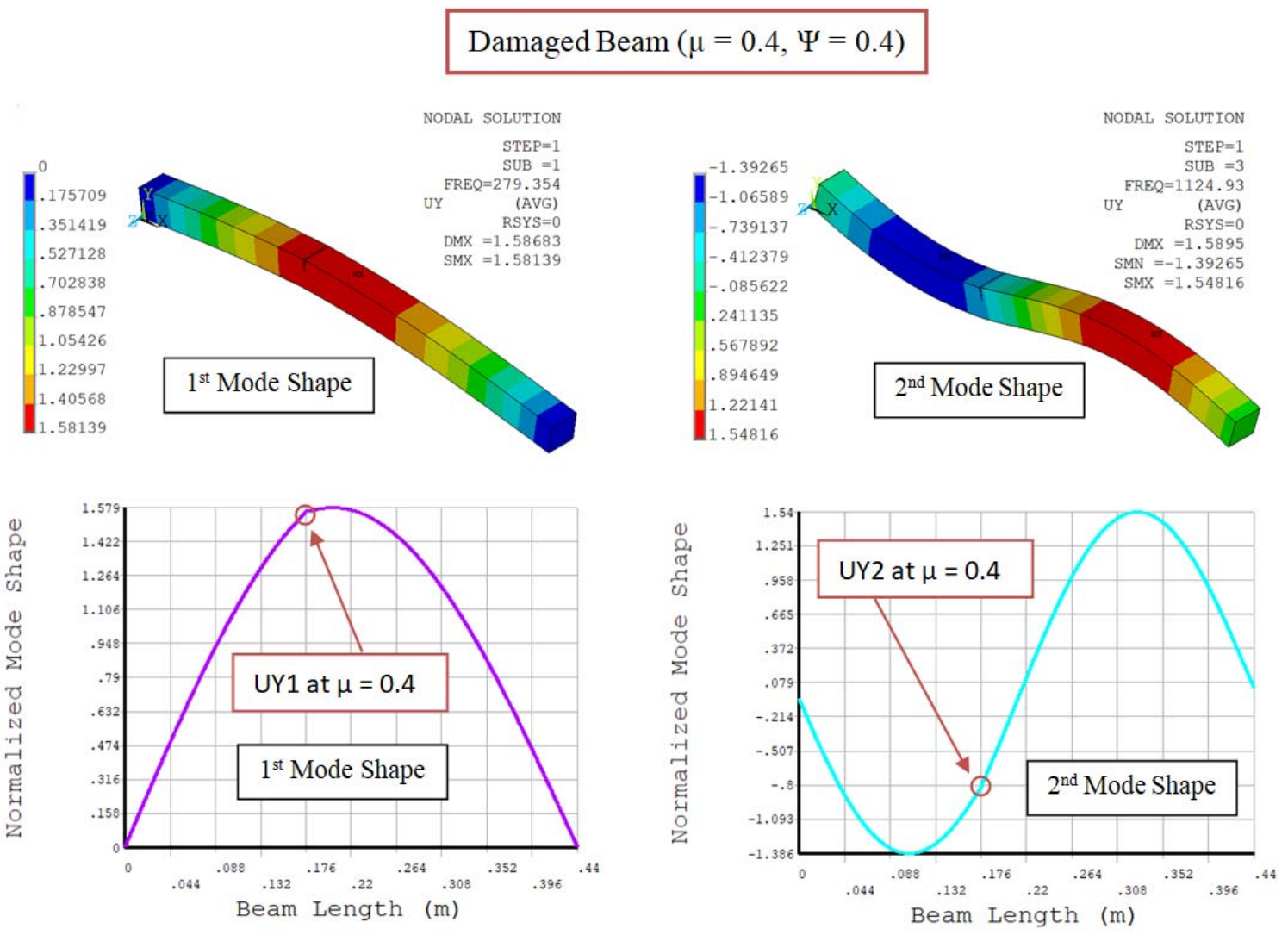

Figure 7: FEA results of first two mode shapes of bending vibration for damaged beam: $\mu=0.4, \Psi=0.4$

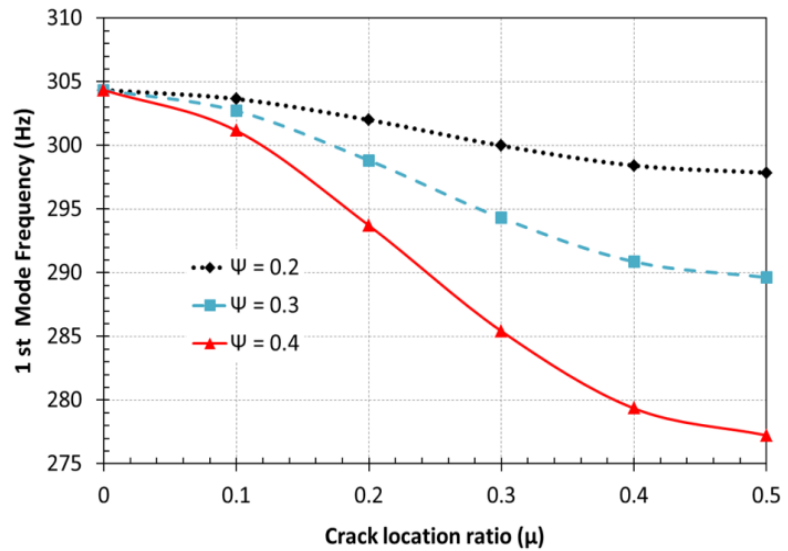

Figure 8: Variation of first bending mode frequency vs. crack location ratio.

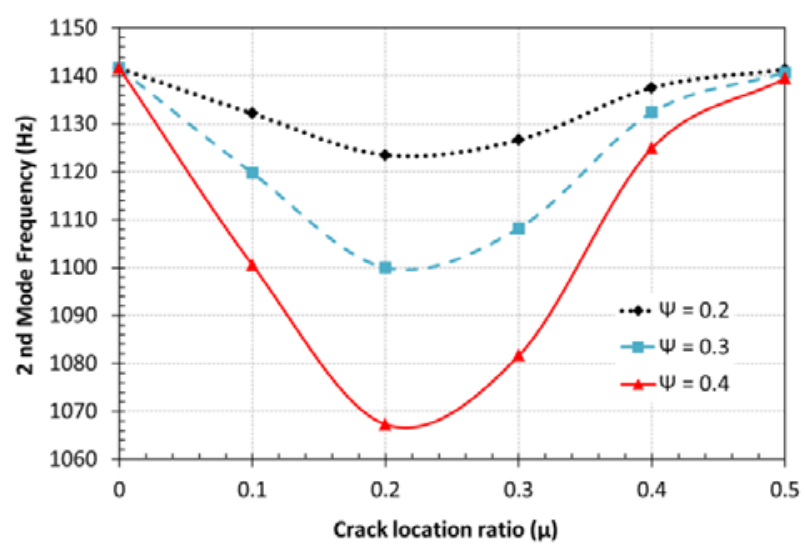

Figure 9: Variation of second bending mode frequency vs. crack location ratio.

\section{CRACK DAMAGE SEVERITY}

$\mathrm{I}$ $\mathrm{n}$ this study, similar to Khalkar [17], static finite element analysis is carried out and static deflection at the midpoint of undamaged and damaged beams is obtained. FEA static deflection plots for some scenarios of damaged beam are shown in Figure 14. Figure 15 shows the variation of static deflection versus crack location ratio and crack depth ratio. From Figure 15, it is observed that when the crack location ratio is increased from the left hand support of the simply supported beam up to midpoint of the beam and crack depth ratio is increased, then static deflection increases. Stiffness of undamaged and damaged beams is computed using the following conventional formula [18]: 


$$
K=\frac{F}{\delta}
$$

where $\mathrm{K}$ is stiffness of beam, $\mathrm{F}$ is load and $\delta$ is static deflection or zero frequency deflection. In this study, the severity of crack can be expressed as crack damage severity (\%) which is estimated using the following equation:

$$
\Delta K=\frac{K_{\text {undamaged }}-K_{\text {damaged }}}{K_{\text {undamaged }}} \times 100
$$

where $\Delta \mathrm{K}$ is crack damage severity, $\mathrm{K}_{\text {undamaged }}$ is stiffness of undamaged beam and $\mathrm{K}_{\text {damaged }}$ is stiffness of damaged beam.

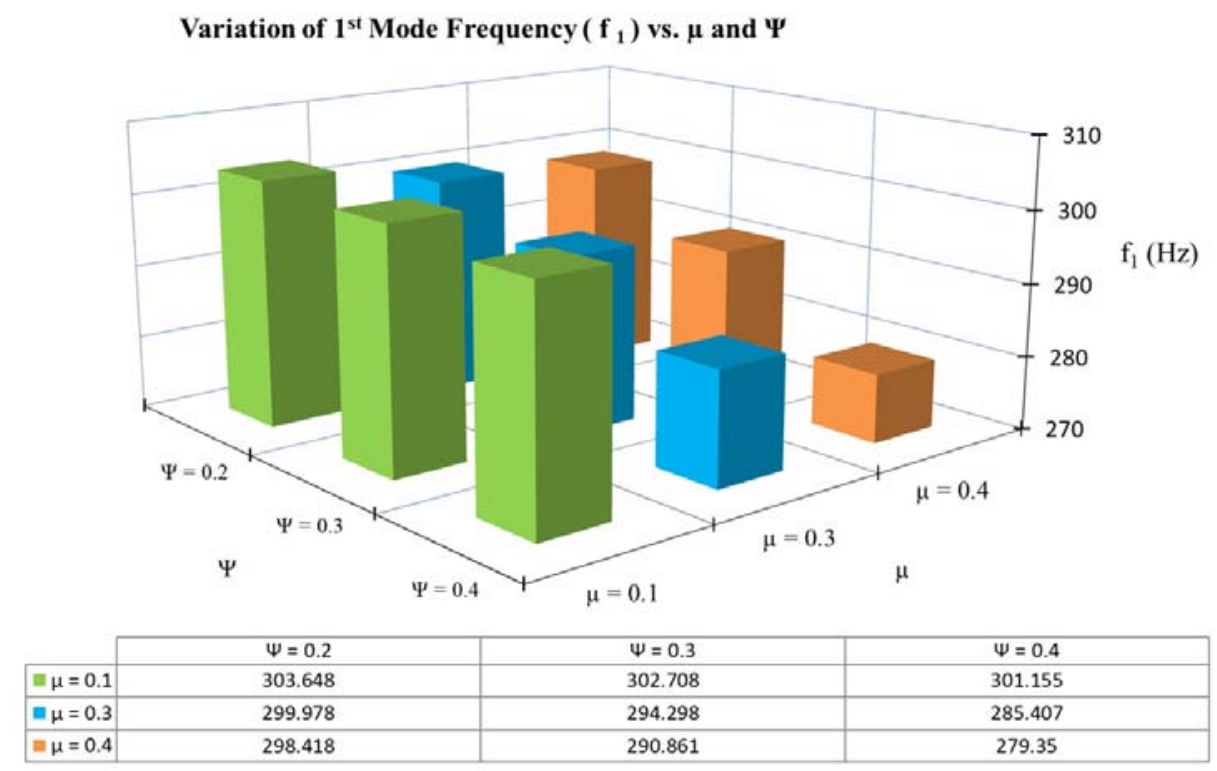

Figure 10: Variation of first bending mode frequency vs. $\mu$ and $\Psi$.

\section{Variation of $2^{\text {nd }}$ Mode Frequency $\left(f_{2}\right)$ vs. $\mu$ and $\Psi$}

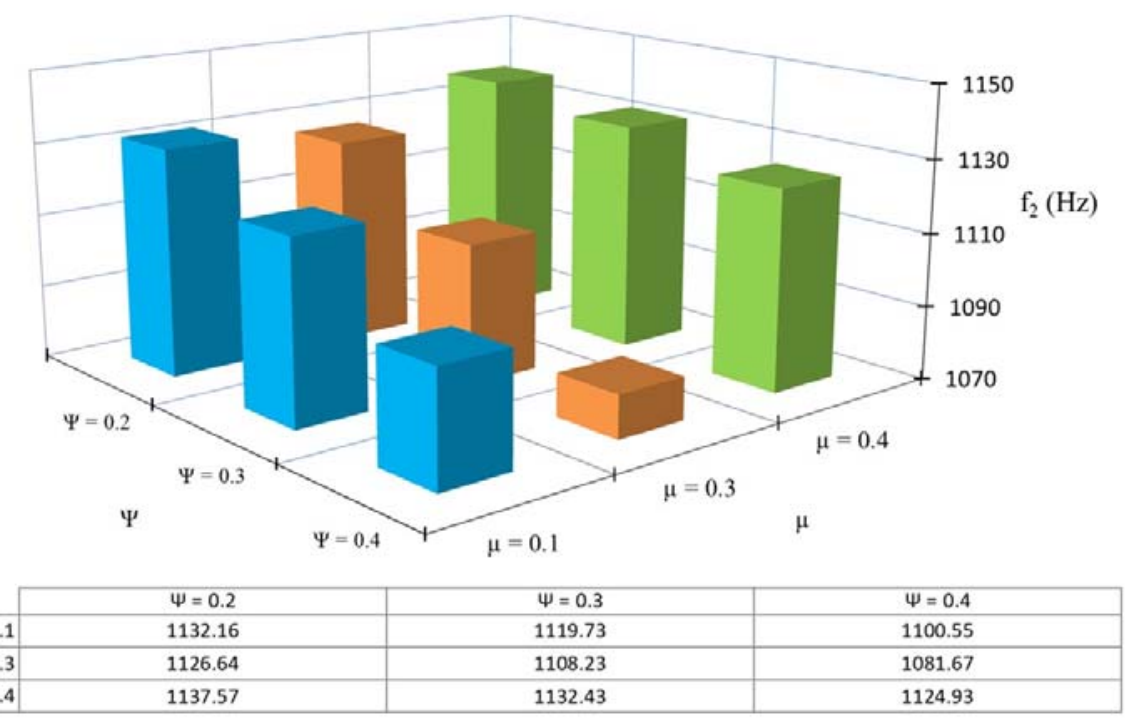

Figure 11: Variation of second bending mode frequency vs. $\mu$ and $\Psi$. 


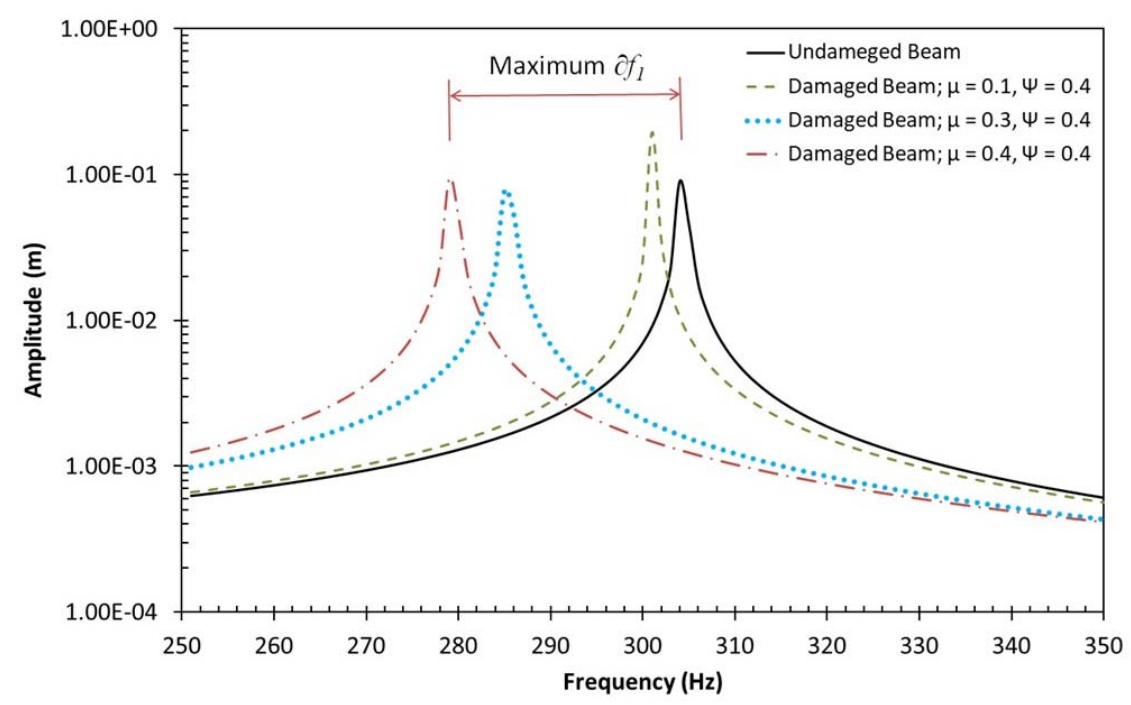

Figure 12: Harmonic response for the damaged beam; $\Psi=0.4$ in the range of $250-350 \mathrm{~Hz}$

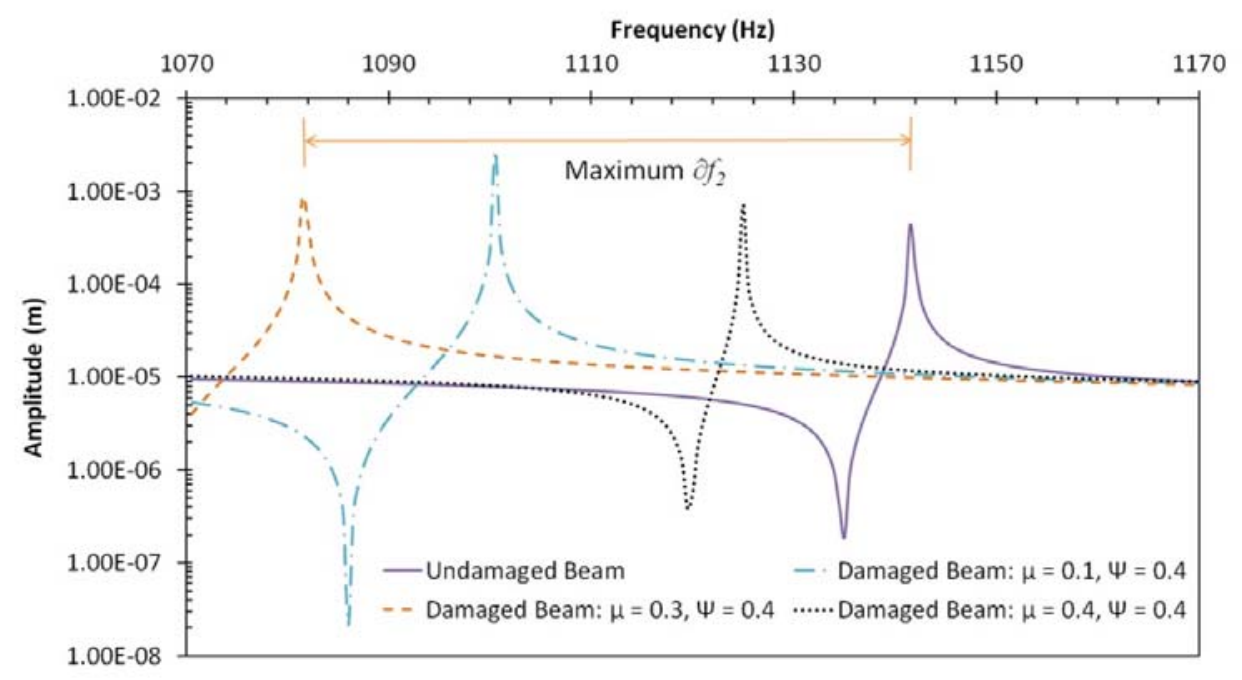

Figure 13: Harmonic response for the damaged beam; $\Psi=0.4$ in the range of $1070-1170 \mathrm{~Hz}$

The variation of crack damage severity versus crack location ratio and crack depth ratio is depicted in Figure 16. From Figure 16, it is found that when the crack location ratio is increased from the left hand support of the simply supported beam up to midpoint of the beam and crack depth ratio is increased, then crack damage severity of the beam increases.

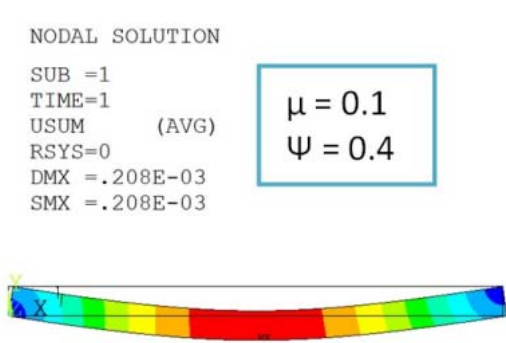

(a)

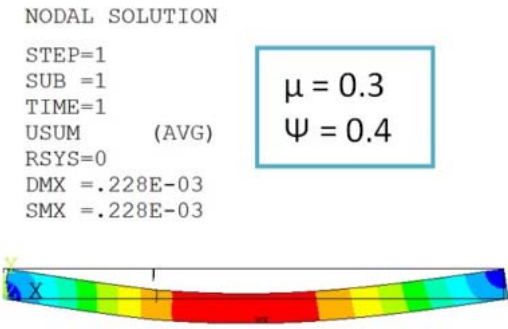

(b)

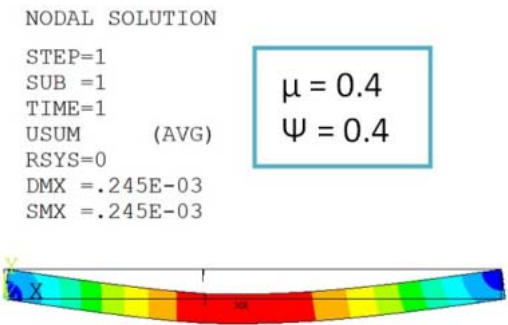

(c)

Figure 14: Static deflection for damaged beam; $\Psi=0.4$ : (a) $\mu=0.1$, (b) $\mu=0.3$, (c) $\mu=0.4$ 


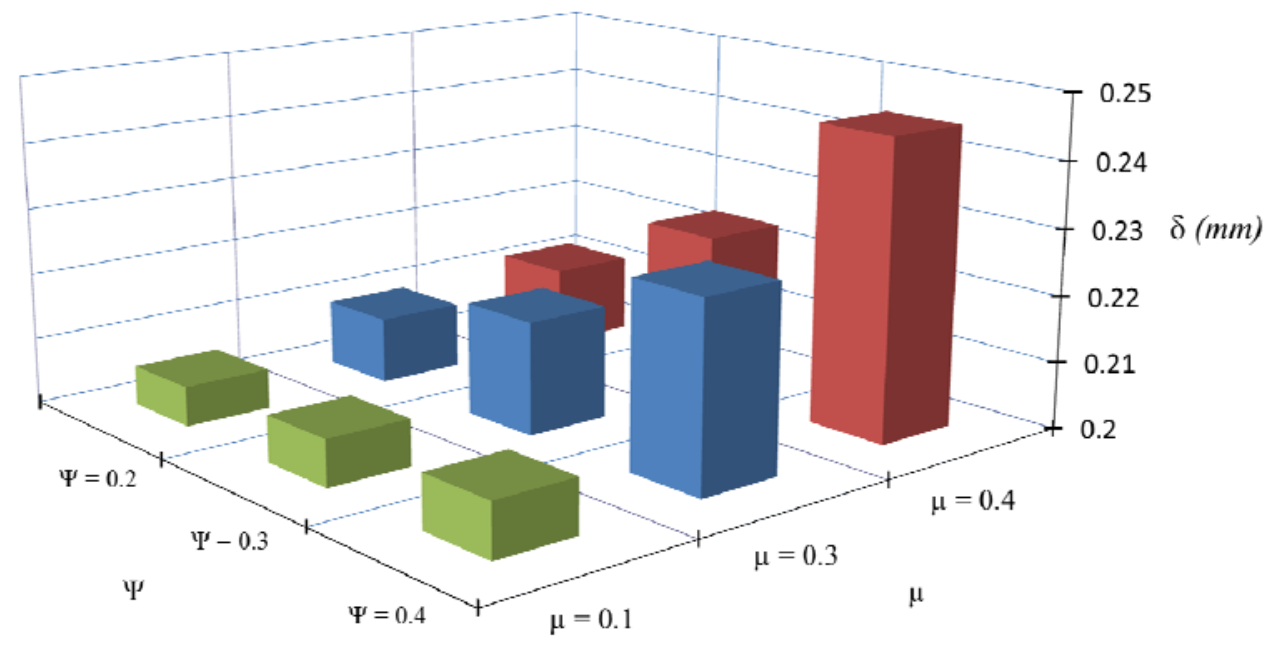

\begin{tabular}{|l|c|c|c|}
\cline { 2 - 4 } \multicolumn{1}{c|}{} & $\psi=0.2$ & $\psi=0.3$ & $\psi=0.4$ \\
\hline$\square=0.1$ & 0.206 & 0.207 & 0.208 \\
\hline$\square \mu=0.3$ & 0.21 & 0.217 & 0.228 \\
\hline$\square \mu=0.4$ & 0.212 & 0.224 & 0.245 \\
\hline
\end{tabular}

Figure 15: Variation of static deflection vs. $\mu$ and $\Psi$

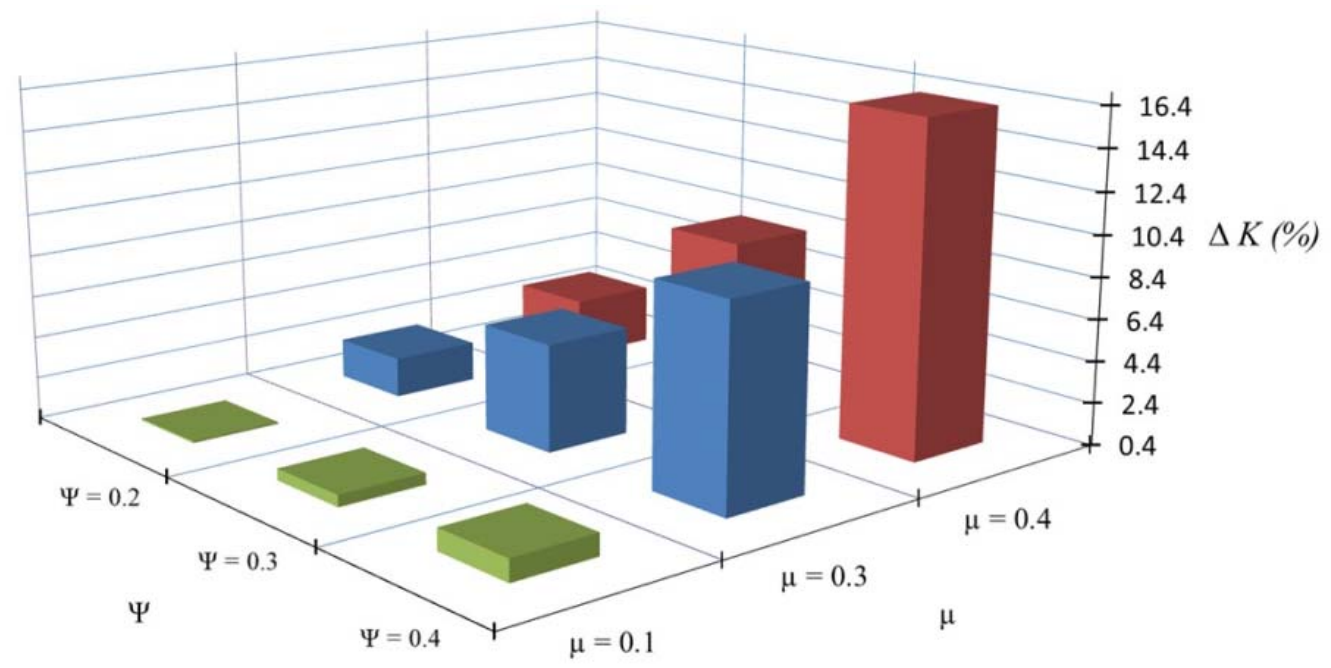

\begin{tabular}{|l|c|c|c|}
\cline { 2 - 4 } \multicolumn{1}{c|}{} & $\Psi=0.2$ & $\psi=0.3$ & $\Psi=0.4$ \\
\hline$\square \mu=0.1$ & 0.48 & 0.96 & 1.44 \\
\hline$\square \mu=0.3$ & 2.32 & 5.54 & 10.05 \\
\hline$\square \mu=0.4$ & 3.28 & 8.48 & 16.34 \\
\hline
\end{tabular}

Figure 16: Variation of crack damage severity vs. $\mu$ and $\Psi$.

\section{DISCUSSION OF RESULTS}

$\mathrm{I}$

$\mathrm{n}$ this section, the correlation between the outcomes of the analysis, i.e., results for the damaged simply supported beam are discussed. When zero frequency deflection is increased, then crack damage severity of the damaged beam increases as shown in Figure 17. As frequency of first mode of bending vibration is decreased, then crack damage severity of the damaged beam increases as shown in Figure 18. For the first two modes of bending vibration, when normalized mode shape at location of crack is increased, then shift between frequencies of damaged and undamaged 
beams increases as depicted in Figures 19 and 20, i.e., $\partial f_{1}$ is proportional to UY1 and $\partial f_{2}$ is proportional to UY2. On the other hand, it is found that the normalized mode shape at location of crack depends on the pattern of mode shape.

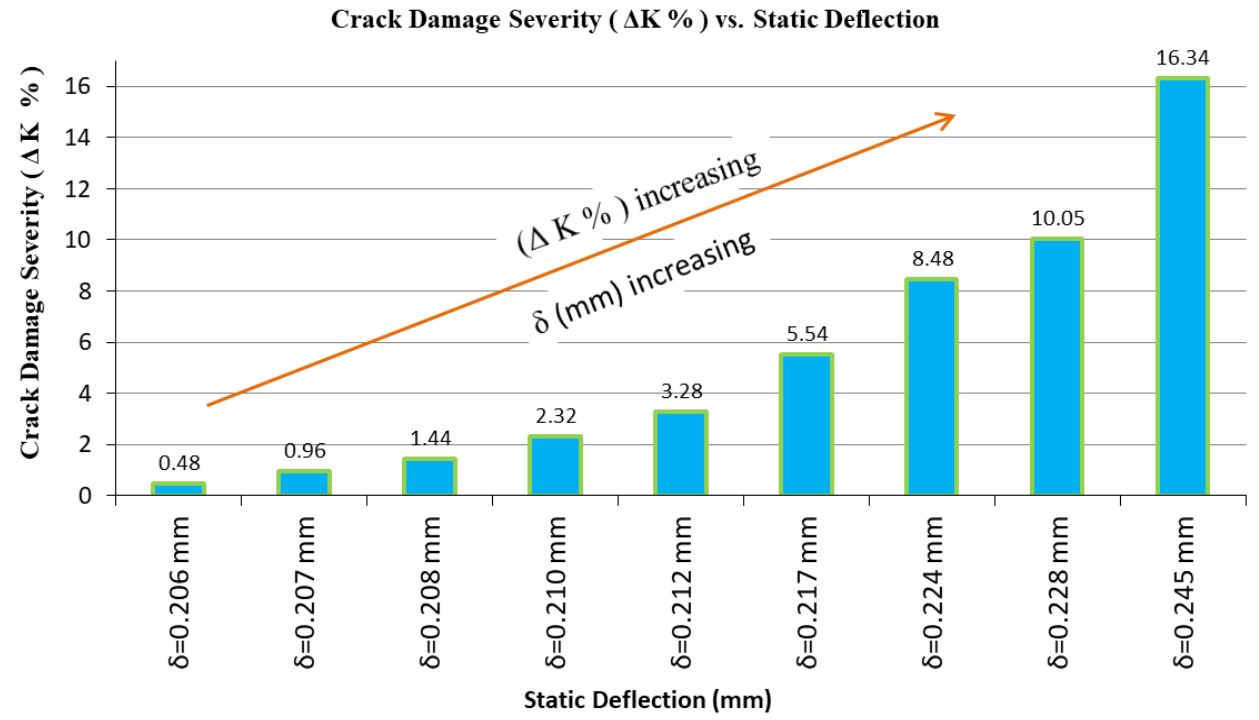

Figure 17: Variation of crack damage severity vs. static deflection

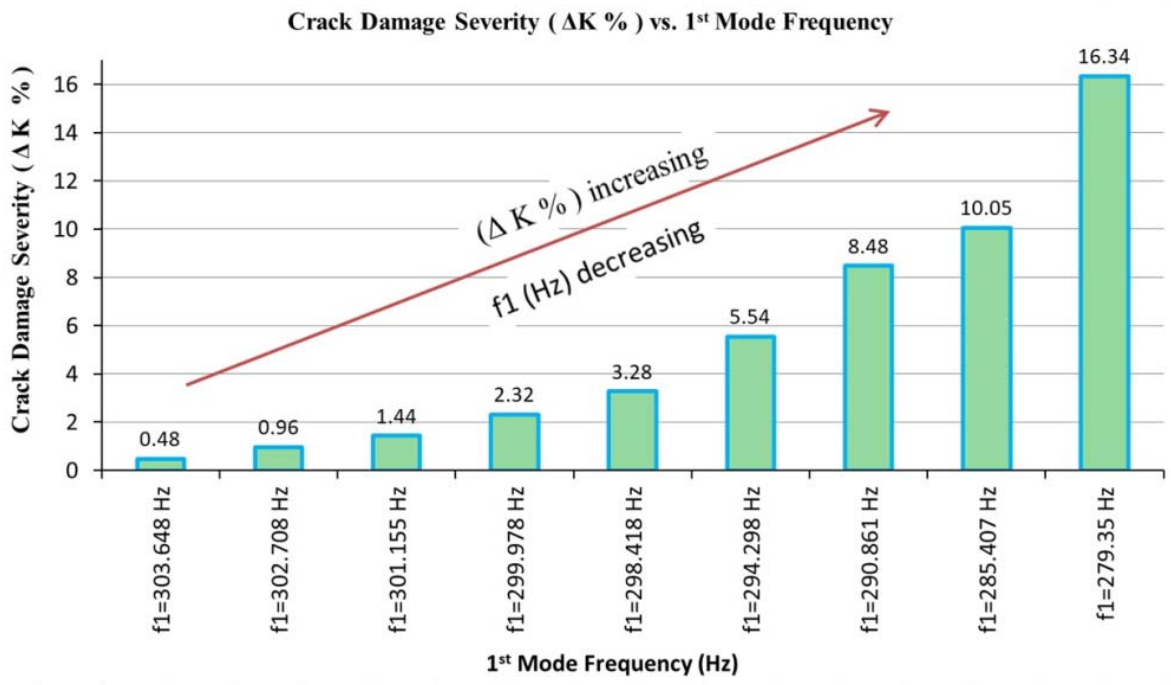

Figure 18: Variation of crack damage severity vs. first mode frequency

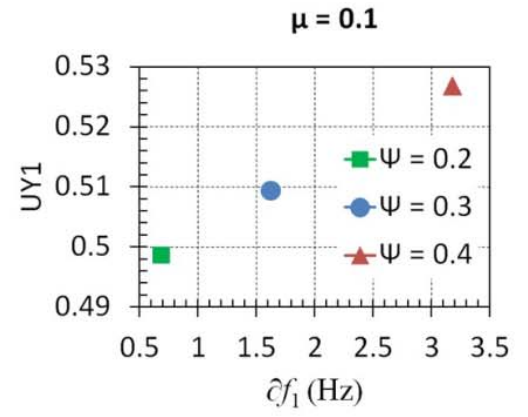

(a)

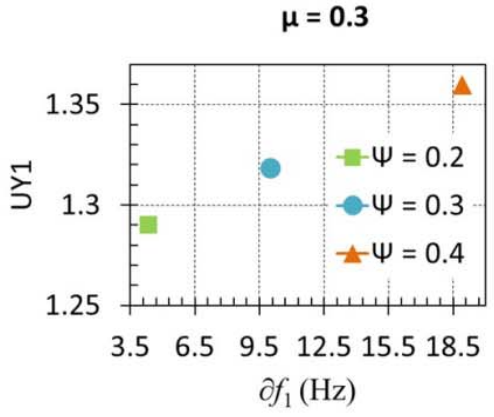

(b)

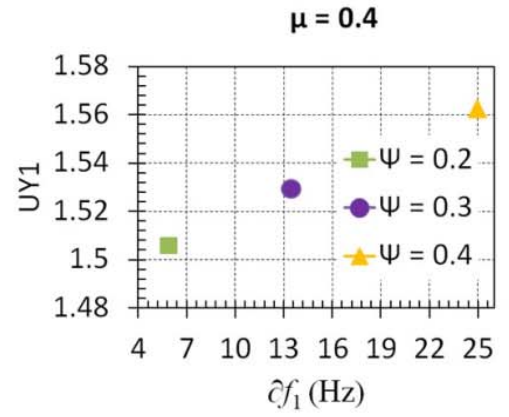

(c)

Figure 19: Plot of UY1 vs. $\partial f_{1}$ 


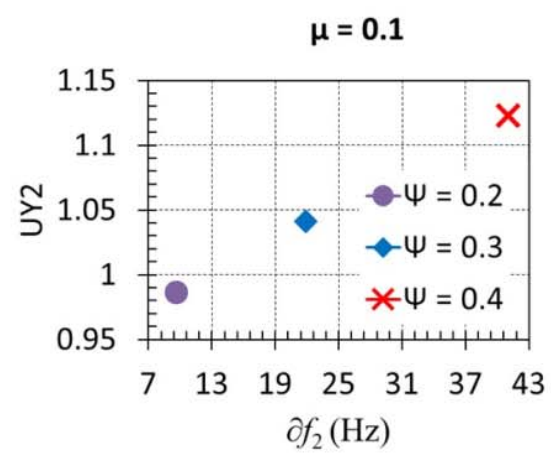

(a)

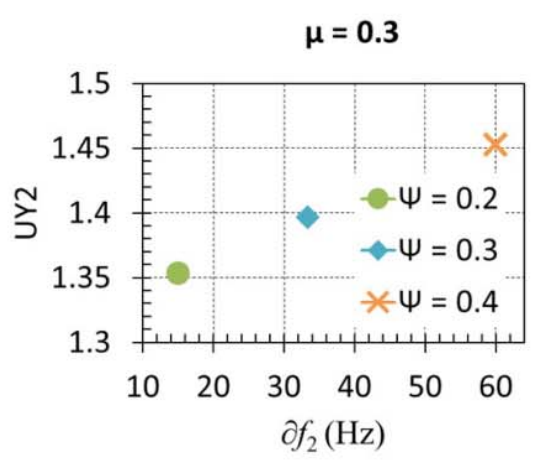

(b)

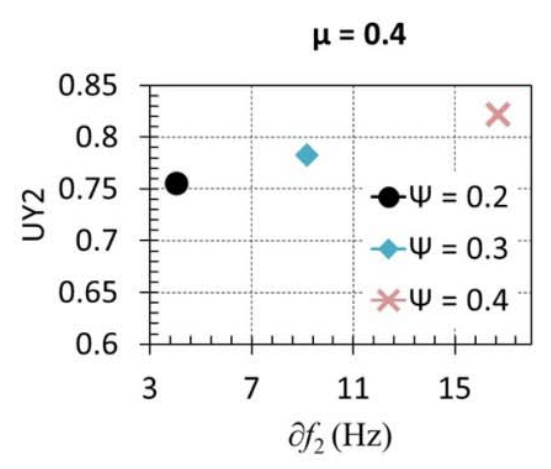

(c)

Figure 20: Plot of UY2 vs. $\partial f_{2}$

\section{CONCLUSION}

$\mathrm{I}$ $\mathrm{n}$ this study, the finite element analysis (FEA) is applied for un-cracked and cracked simply supported beams to investigate crack damage severity and its correlation to static and dynamic parameters. For first two mode shape of bending vibration for undamaged and damaged beams, frequencies are calculated and also mode shape pattern is obtained. Furthermore, frequency response diagram is obtained to determine the shift in frequencies between undamaged and damaged beams. It is observed that the pattern of mode shape seems to be an effective in the determining the value of normalized mode shape at location of crack. Any decrease in the frequency is largest, i.e. maximum shift between undamaged and damaged beams in frequency response diagram is due to largest value of normalized mode shape at location of crack. Based on FEA static deflection, stiffness of damaged beam was computed and crack damage severity is estimated. From the results, it is found that when static deflection is increased and first mode frequency is decreased, then crack damage severity (\%) increases. Furthermore, in this study, pattern of mode shape played a vital role for interpreting decreasing or increasing natural frequencies for damaged beam.

\section{REFERENCES}

[1] Orhan, S. (2007). Analysis of free and forced vibration of a cracked cantilever beam. NDT E Int., 40, pp. 443-450, DOI: $10.1016 /$ j.ndteint.2007.01.010.

[2] Zeng, J., Ma, H., Zhang, W., Wen, B. (2017). Dynamic characteristic analysis of cracked cantilever beams under different crack types. Eng. Fail. Anal. 74, pp. 80-94, DOI: 10.1016/j.engfailanal.2017.01.005.

[3] Rezaee, M., Hassannejad, R. (2011). A new approach to free vibration analysis of a beam with a breathing crack based on mechanical energy balance method. Acta Mech. Solida Sin. 24 (2), pp. 185-194,

DOI: 10.1016/S0894-9166(11)60020-7.

[4] Owolabi, G.M., Swamidas, A.S.J., Seshadri, R. (2003). Crack detection in beams using changes in frequencies and amplitudes of frequency response functions. J. Sound Vib. 265(1), pp. 1-22, DOI: 10.1016/S0022-460X(02)01264-6.

[5] Soliman, E.S.M.M. (2019). Investigation of crack effects on isotropic cantilever beam. J. Fail. Anal. Prev. 19(6), pp. 1866-1884. DOI: 10.1007/S11668-019-00796-7.

[6] Andreaus, U., Casini, P. (2016). Identification of multiple open and fatigue cracks in beam-like structures using wavelets on deflection signals. Contin. Mech. Thermodyn. 28, pp. 361-378, DOI: 10.1007/s00161-015-0435-4.

[7] Sayyad, F.B., Kumar, B., Khan, S.A. (2012). Approximate analytical method for damage detection in free-free beam by measurement of axial vibrations. Int. J. Damage Mech. 22(1), pp. 133-142, DOI: 10.1177/1056789512440897.

[8] Sayyad, F.B., Kumar, B. (2010). Theoretical and experimental study for identification of crack in cantilever beam by measurement of natural frequencies. J. Vib. Control 17(8), pp. 1235-1240, DOI: 10.1177/1077546310384005.

[9] Bhaurkar, V.P., Thakur, A.G. (2019). Investigation of crack in beams using anti-resonance technique and FEA approach. J. Eng. Des. Technol. 17(6), pp. 1266-1284, DOI: 10.1108/JEDT-10-2018-0179. 
[10] Khalkar, V., Ramachandran, S. (2017). Paradigm for natural frequency of an un-cracked cantilever beam and its application to cracked beam. ARPN J. Eng. Appl. Sci. 12(6), pp. 1714-1729

[11] Barad, K.H., Sharma, D.S., Vyas, V. (2013). Crack detection in cantilever beam by frequency based method. Procedia Eng. 51, pp. 770-775, DOI: 10.1016/j.proeng.2013.01.110.

[12] Mungla, M.J., Sharma, D.S., Trivedi, R.R. (2016). Identification of a crack in clamped-clamped beam using frequencybased method and genetic algorithm. Procedia Eng. 144, pp. 1426-1434, DOI: 10.1016/j.proeng.2016.05.174.

[13] Sayyad, F.B., Kumar, B. (2011). Identification of crack location and crack size in a simply supported beam by measurement of natural frequencies. J. Vib. Control 18(2), pp. 183-190, DOI: 10.1177/1077546310395979.

[14] Rizos, P.F., Aspragathos, N., Dimarogonas, A.D. (1990). Identification of crack location and magnitude in a cantilever beam from the vibration modes. J. Sound Vib. 138(3), pp. 381-388, DOI: $10.1016 / 0022-460 \mathrm{X}(90) 90593-O$.

[15] Dimarogonas, A.D. and Paipetis, S.A. (1983). Analytical Methods in Rotor Dynamics, London, Elsevier Applied Science.

[16] Petrova, D.K. (2014). Vibration-based methods for detecting a crack in a simply supported beam. J. Theor. Appl. Mech. 44(4), pp. 69-82, DOI: 10.2478/jtam-2014-0023.

[17] Khalkar, V. (2018). Paradigm for natural frequency of an un-cracked simply supported beam and its application to single-edged and multi-edged cracked beam. Vib. Phys. Syst. 29, 2018028

[18] Khalkar, V., Ramachandran, S. (2018). The effect of crack geometry on stiffness of spring steel cantilever beam. J. Low Freq. Noise Vib. Act. Control 0, pp. 1-13, DOI: 10.1177/1461348418765959. 